Int. J. Electrochem. Sci., 14 (2019) $5924-5937$

International Journal of

ELECTROCHEMICAL

SCIENCE

WWW.electrochemsci.org

\title{
Comparison Study of Partial Least Squares Regression Analysis and Principal Component Analysis in Fast-Scan Cyclic Voltammetry
}

\author{
Jaekyung Kim ${ }^{1}$, Yoonbae $\mathrm{Oh}^{2}$, Cheonho Park ${ }^{1}$, Yu Min Kang ${ }^{1}$, Hojin Shin ${ }^{1}$, \\ In Young Kim ${ }^{1}$, and Dong Pyo Jang, ${ }^{1, *}$ \\ ${ }^{1}$ Department of Biomedical Engineering, Hanyang University, Seoul, South Korea \\ ${ }^{2}$ Department of Neurologic Surgery, Mayo Clinic, Rochester, MN, USA \\ *E-mail: dongpjang@hanyang.ac.kr
}

doi: $10.20964 / 2019.07 .03$

Received: 24 February 2018 / Accepted: 25 March 2019 / Published: 10 June 2019

\begin{abstract}
Both principal component regression (PCR) and partial least squares regression (PLSR) have been commonly used to predict neurochemical concentrations from measurements of fast-scan cyclic voltammetry (FSCV). However, a comparison of the accuracy of the above methods for FSCV analysis is yet to be demonstrated. In this work, we compare the concentration estimation performance of PCR and PLSR in an analysis of FSCV data. Using conventional FSCV, we recorded in vitro background-subtracted cyclic voltammograms from five neurochemicals i.e., dopamine, ascorbic acid, 3,4-dihydroxyphenylacetic acid, and serotonin, and $\mathrm{pH}$ change, with five concentrations of each substance and five $\mathrm{pH}$ values. The results showed that the absolute error (AE) and mean absolute percentage error (MAPE) were significantly smaller on average when the concentration of a single substance was predicted using PLSR compared with the use of PCR. As a further evaluation of PCR and PLSR, we compared the predictions of the concentrations of mixtures using PCR and PLSR. The AE and MAPE in the predictions obtained using PLSR were significantly smaller than those obtained using PCR. Across the single substance and the four types of mixtures, compared with PCR, PLSR showed not only higher accuracy in the prediction of concentrations but also higher selectivity. Therefore, PLSR should be preferred over PCR as a more reliable tool to analyze FSCV data.
\end{abstract}

Keywords: Fast-scan cyclic voltammetry (FSCV); Principal component analysis (PCR); Partial least squares regression (PLSR); Neurochemical

\section{$\underline{\text { FULL TEXT }}$}

(C) 2019 The Authors. Published by ESG (www.electrochemsci.org). This article is an open access article distributed under the terms and conditions of the Creative Commons Attribution license (http://creativecommons.org/licenses/by/4.0/). 